وأختير تركيز المطفر الذي يعطي 90\% نسبة الذبة

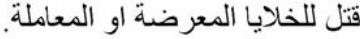

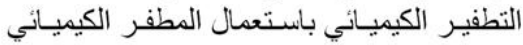

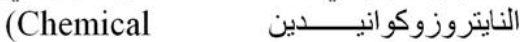
Mutagensis by using Nitrosoguanidine (NIG)) الطريقة الموصوفة من قبل[10] و اختير تركيز

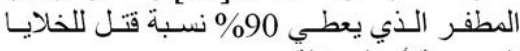
المعرضة أو المعاملة

تحديد الظروف البيئية المثلى لانتاج الفاـ اميليز: تعيين المصدر الكربوني الامثل لانتاج الانزئيم: الفئيز

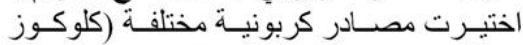

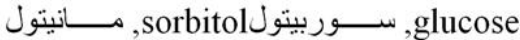
maltose, mannitol

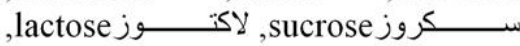

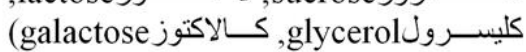
وبتركيز 1\% لتعيين المصدر الكربوني الامثل

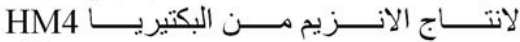
B.licheniformis HM14,

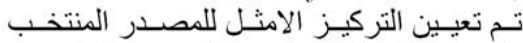

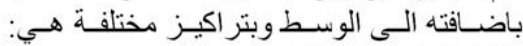
$\%(2.5,2.0,1.5,1.0,0.5,0)$

تعيـين المصـــر النـايتروجيني الامثـل لانتـاج

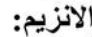

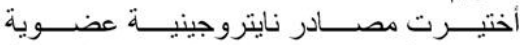

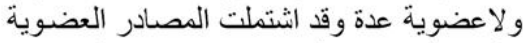

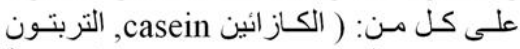

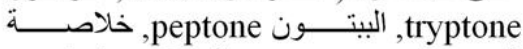
الخميرة yeast extract و الجيلاتينو و و و

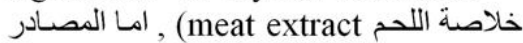

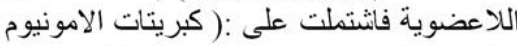

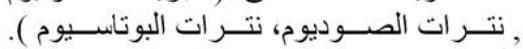

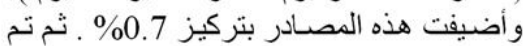

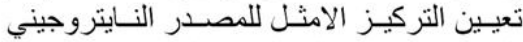
المنتخب باضافته الى الوسط المنتخب وبتر اكيز مختلفة هي: (2.0,1.5,1.0.7,0.5,0.3)\%

تأثيرتر اكيز مختلفة من كلوريد الكالسيوم في انتاج

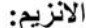

درس نأثير تر اكيز مختلفة من كلوريد الكالسيوم وهي : (0.05,0.03,0.02,0.015,0.01,0

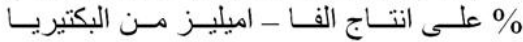
B.lichinformis HM4, HM14 في الوسط الإن الانتاجي السائل لتحديد التركيز الامثل لي.

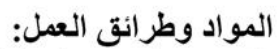
تثخيص العزلات المحلية المنتجة لأنزيم الفا ـ ـ الميز

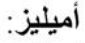

تم نثخيص العزلات المحلية المنتجة لأنزيم الفـا

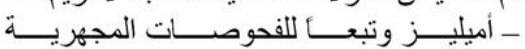

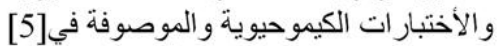
إختبار قدرة العزلات البكتيرية على النتاج أنزيم

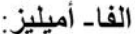

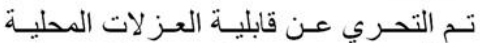

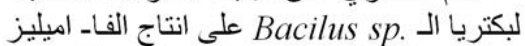

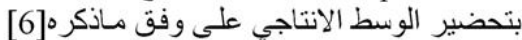

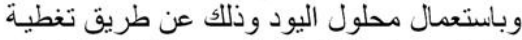

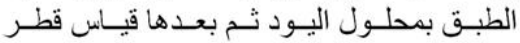

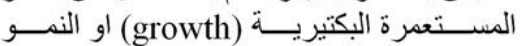

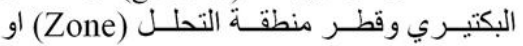

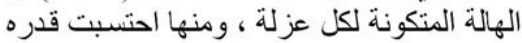

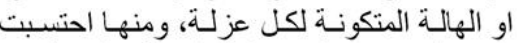

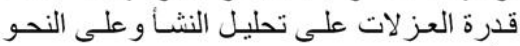

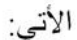

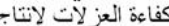
الأنزيمات المحللة للنشا = قطر منطقة التحلل (الهالة النتكي نة) قطر المنتعمرة البكتير يتّة(النمو البكتيري)

أما إختيار العزلة الاكفاً على إنتاج أنزيم الفا-

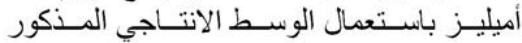

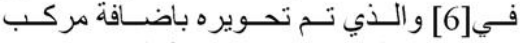

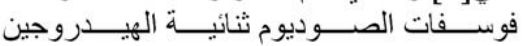
\% 0.16 وبتركيز $\mathrm{NaH}_{2} \mathrm{PO}_{4} .2 \mathrm{H}_{2} \mathrm{O}$ تقدير فعالية أنزيم ألفا_أميليز:

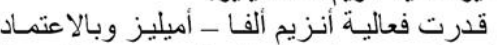

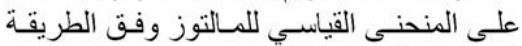

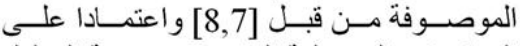

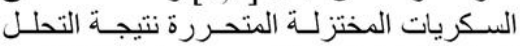

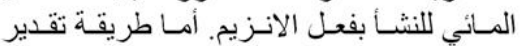
البروتين فقد قدرت وفق الطريقة الموصوفة من

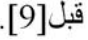

التطفير الوراثي (Mutagensis): التطفيــر الفيزيــائي باســتعمال الاثــــة فــوق (Physical Mutagensis by البنفسـية و أتبعت using ultraviolet light (uv.))

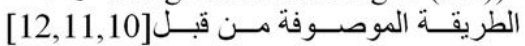

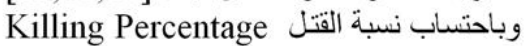
بعدد الخلايا المتبقية وتطبيق القانون الاتي:

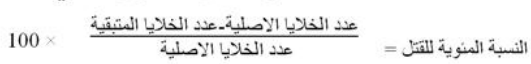


التحري عن قابليـة العزلات المحليـة لبكتيريـا Bacillus sp. الوسط الصلب:

Bacillus sp. sp. أخضـعت عـز لات بكتيريــا

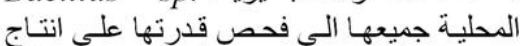

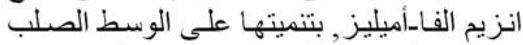

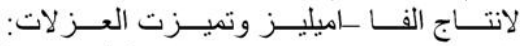
(H27,H24,H18,H17,H14) العالي الانزيم مـع امتلاكهـا نسبة تحلل مقدار هـان

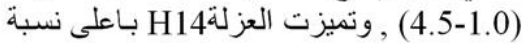

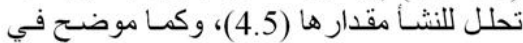
الجدول (1) و الثكل(2).

الجدول (1): الغربلة شبه الكمية لعزلات العـايلة

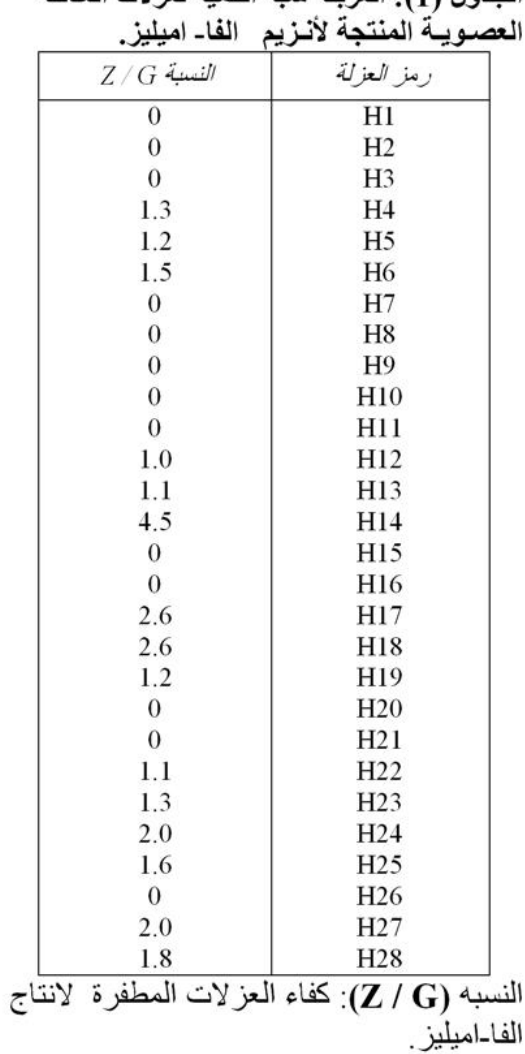

Z : قطر الهالة المتكونة (ملم). G
تعيبين الرقم الهيدروجيني الابتدائي الامثل لانتاج

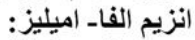

حضر الوسط الامثل للانتاج بارقام هيدروجينية

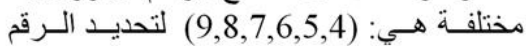
الهيدروجيني الامثل لانتاج انزيم الفاـ اميليز من

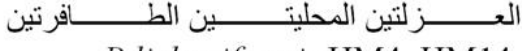
B.licheniformis HM4, HM14

تعيبين درجـة الحرارة المثلى لانتـاج انـزيم الفـــ

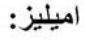
حضن الوسط الامثل لانتاج الانزيم في درجـات حر ارية مختلفة هي: (65,60,55,50,45,40) مُلتحديد درجـة الحر ارة المثلى لانتـاج الانزيم

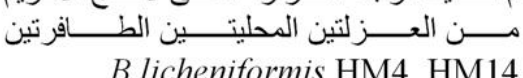

تحديد مدة الحضـانة المثلى لانتاج انزيم الفـااميليز:

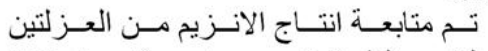
B.licheniformis المليتـين الطـين ) : بــدمد زمنيـة مختلفـة HM4, HM14 (96,72,48,24 سـاعة لتحديـــ المـــة الزمنيـة

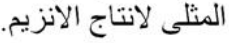
النتانج والمناقثة: تشخيص الجنس Bacillus: أمكن في هذه الدر اسـة الحصبول على العـ (28)

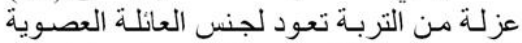

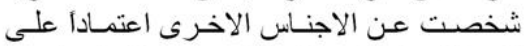

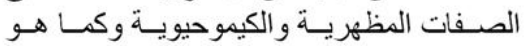

مذكور في[5] وكما موضح في الشكل (1).

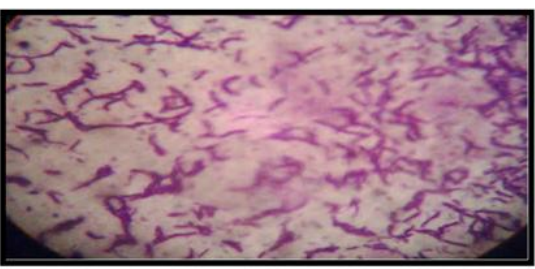

الثكل (1): الخلايا العصوية الموجبة لصبغة غرام للعزلة المحلية 14 B. licheniformis H منماة

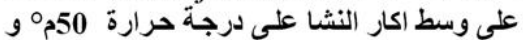
لمدة 24 ساعة وبقوة تكبير ( 100 X 1 ). 
تشـخيص العـزلات الكفـوزة المنتجــة لاتـزيم الفــااميليز:

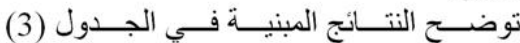

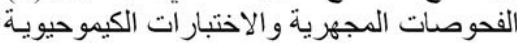

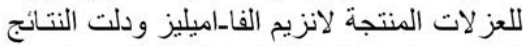

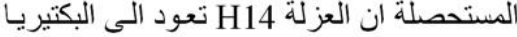
B.licheniformis $\mathrm{H} 14$

الجدول (3) الإختبارات المجهرية و الكيموحيوية لئلية

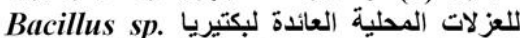

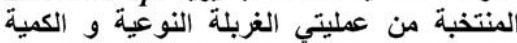
المنتجة لأنزيم ألفا ـ أميليز و تبعاً للمفتاح المبسط

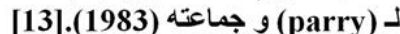

\begin{tabular}{|c|c|c|c|c|c|c|c|}
\hline كاعلدر | & س. سكر & قد & | سيركي & $\mid$\begin{tabular}{c|c|} 
\\
\end{tabular} & |حلخس & $\varepsilon \mu$ & |j, \\
\hline+ & سصوي & 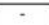 & + & + & + & B.licheniformis & $\mathrm{H}_{44}$ \\
\hline+ & ستوئ & + & + & - & - & Bacillus \$p. & $\mathrm{H}_{12}$ \\
\hline+ & سصوي & + & + & - & - & Bacillus $\$$. & $\mathrm{H}_{12}$ \\
\hline+ & بنصوي & - & + & + & + & B. licheniformis & $\mathrm{H}_{24}$ \\
\hline+ & بنشوي & $\cdot$ & + & + & + & B.licheniformis & $\mathrm{H}_{27}$ \\
\hline
\end{tabular}

B.licheniformis H14 تحسين انتاجية العزلة الفيزية باستخدام التطفير الفيزيائي والكيميائي:

تعديد المـدة الزمنيـة المثلى للتطفير بالاشـعة فوق البنفسجية:

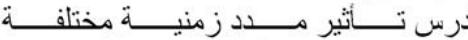

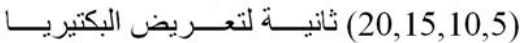
B.licheniformis H14

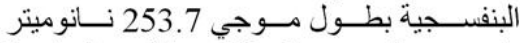
واختيرت المدة 10 ثانيـة كونها المدة المناسبة

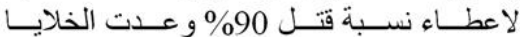

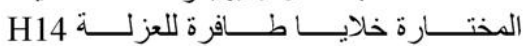
B.licheniformis 92.5\% أدخلت المستعمر ات الطافرة لعمليتي

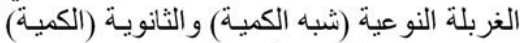

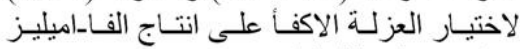
واظهرت العزلة الطافرة كفـاءة عاليـة في انتـاج انزيم الفـاـاميليز قياسـا

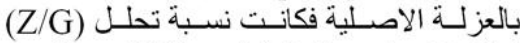
لها(7.6) وبلغت الفعالية النوعية للانزيم المنتج

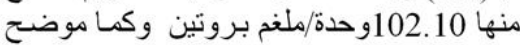
في الجدولين (4) و( 5 (5).

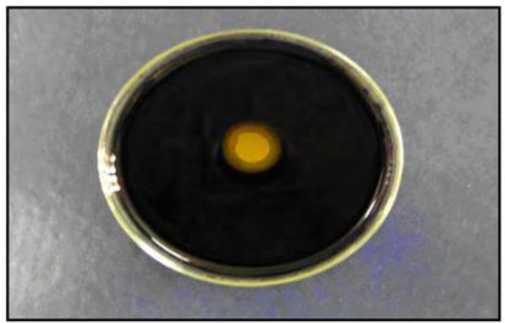

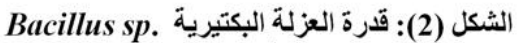

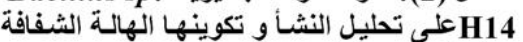
حول المستعمرة البكتيرية.

اختبار العزلة الاكفأ في انتاج ألفـــ أميليز في

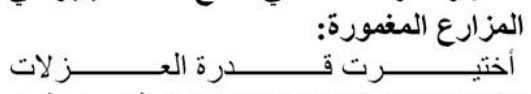

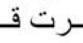

(H27,H24,H18,H17,H14)

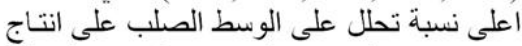

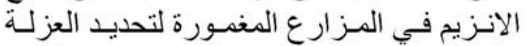

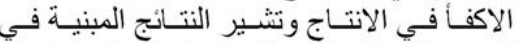

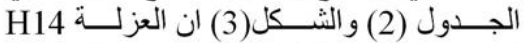

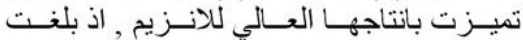

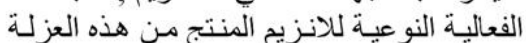

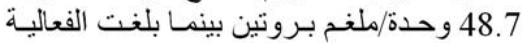

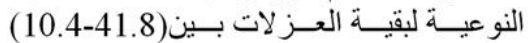
وحدة/ملغخ بروتين.

الجــدول ( 2) الغربلــة الكميــة لعـزلات العائلـــة العصوية المنتجة للألفا ـ اميليز.

\begin{tabular}{|c|c|}
\hline رالفعالية النوعية (وحدة/منغع بروتين) & H14 \\
\hline 48.70 & H24 \\
41.8 & H17 \\
34.80 & H18 \\
33.0 & H27 \\
10.4 &
\end{tabular}

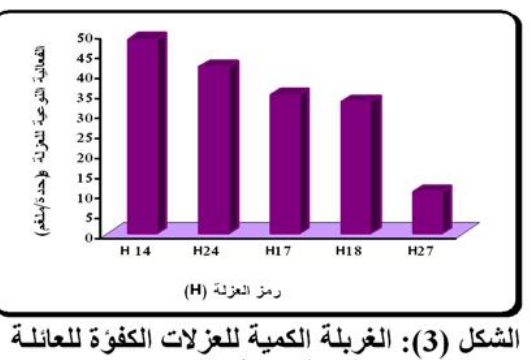

العصوية المنتجة للألفا - أميليز 


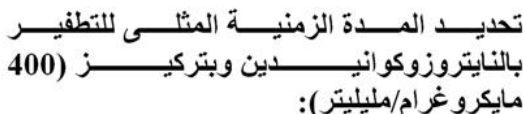

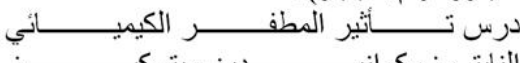

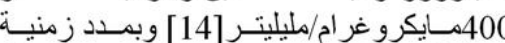

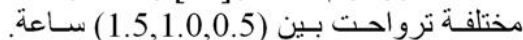

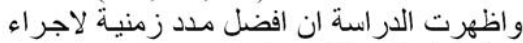

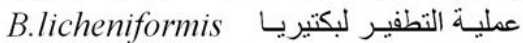

كانت بعد مرور ساعة واحدة من المعاملة

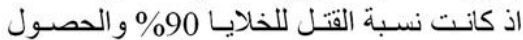

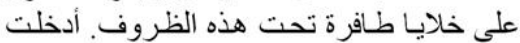

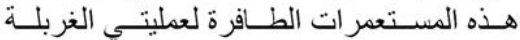

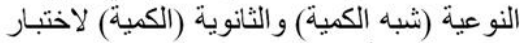

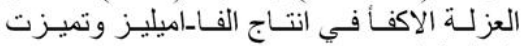

B.licheniformis العزلــة الطـافرة

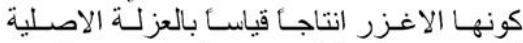

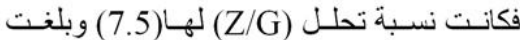
الفعاليـة النوعيـة للانـزيم المنتج منهـ 100.94

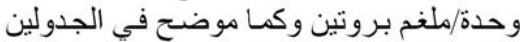

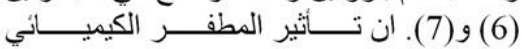

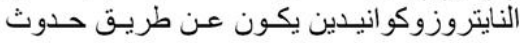
طفرة تحول(انقلاب) Transition Mutation

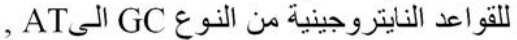

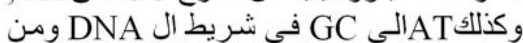

ثم حدوث الطفرة[10]

B. الجدول(6) الغربـــة شبه الكميـة للعزلات licheniformis H14

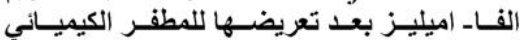

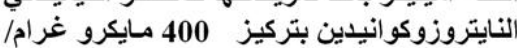

\begin{tabular}{|c|c|}
\hline النسبة G/ Z & رمز العزلة \\
\hline 3.12 & HMl \\
\hline 3.37 & HM2 \\
\hline 5.5 & HM3 \\
\hline 7.5 & HM4 \\
\hline 3.33 & HM5 \\
\hline 1.56 & HM6 \\
\hline 6.0 & HM7 \\
\hline 5.0 & HM8 \\
\hline 5.0 & HM9 \\
\hline 3.33 & HM10 \\
\hline
\end{tabular}

Z Z : قطر الهالة المتكونة (ملح).

G قطر المستعمرة البكتيرية (ملم) .
B. الجدول ( 4 ) : الغربلة شبه الكمية لعزلات licheniformis H14 الفا - اميليزبعد تعريضها للاشعة فوق البنفسجية.

\begin{tabular}{|c|c|}
\hline النسبة / / & رسز العزلة \\
\hline 3.37 & HMI \\
\hline 5.0 & HM2 \\
\hline 4.14 & HM3 \\
\hline 3.12 & HM4 \\
\hline 3.71 & HM5 \\
\hline 3.0 & HM6 \\
\hline 6.0 & HM7 \\
\hline 5.0 & HM8 \\
\hline 5.0 & HM9 \\
\hline 5.0 & HM10 \\
\hline 4.66 & HMII \\
\hline 5.5 & HM12 \\
\hline 6.0 & HM13 \\
\hline 7.6 & HMl4 \\
\hline 5.4 & HM15 \\
\hline
\end{tabular}

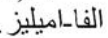

Z Z: قطر الهالة المتكونة (ملم)

G : قطر المنتعمرة البكتيرية (ملم).

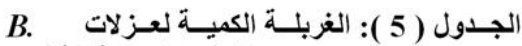

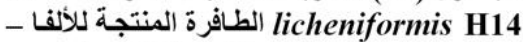
اميليز بعد تعريضها للأشعة فوق البنفسجية.

\begin{tabular}{|c|c|}
\hline (وحثد/ملغن بروتثين) & رمز العزلة \\
\hline 45.73 & HM1 \\
\hline 77.58 & HM2 \\
\hline 71.35 & HM3 \\
\hline 44.55 & HM4 \\
\hline 45.97 & HM5 \\
\hline 37.12 & HM6 \\
\hline 43.51 & HM7 \\
\hline 75.50 & HM8 \\
\hline 79.20 & HM9 \\
\hline 87.00 & HM10 \\
\hline 86.20 & HM11 \\
\hline 87.00 & HM12 \\
\hline 71.25 & HM13 \\
\hline 102.10 & HM14 \\
\hline 69.61 & HM15 \\
\hline
\end{tabular}

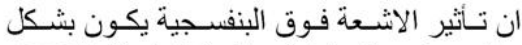
مباثــر فـي المــادة الور اثيــة للخليـة (DNA) Deoxyribnucleicacid

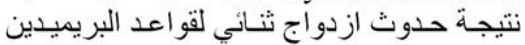

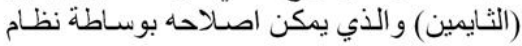

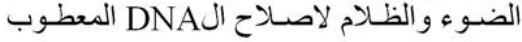

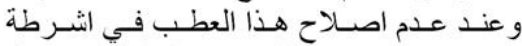

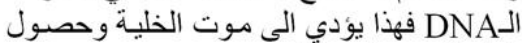
القتل للخلايا المعاملة] [12]. 


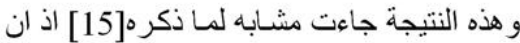

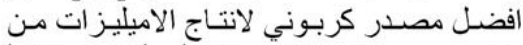

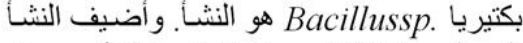

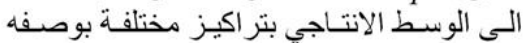
مصدر أ كربونيا لانتاج الفـاـاميليز من العزيز لتينين

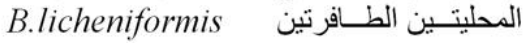
. B.licheniformis HM4 و HM14

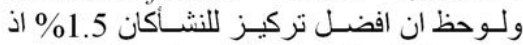

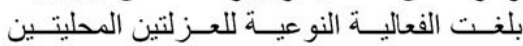

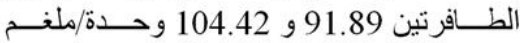
بروتين و على التو الي وكمـا موضتح في الثكل

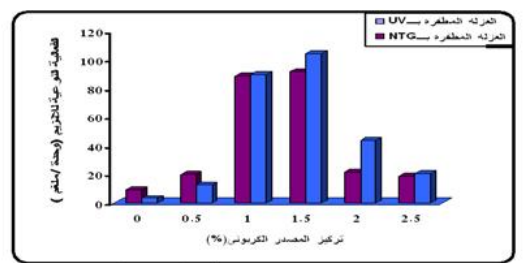

الثكل (5): تحديد تركيز النشأ الأمثل لأنتاج الفا ـ

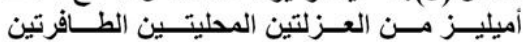
و B. licheniformisHM14 .B. licheniformisHM4

تحديـد المصـدر النـايتروجيني الامثل لانتـاج

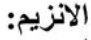

أختيرت مصادر نتروجينية عضوية و لاعضوية

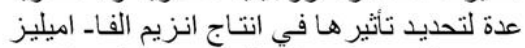

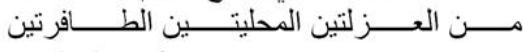
وB.licheniformis HM14 B.licheniformis HM4 المصسادر بتركيز 0.7\% اللى الوسط الانتاجي. أظهرت النتائج ان البيتون هو الاكفأ في انتاج النياج

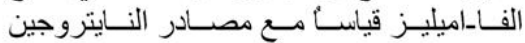

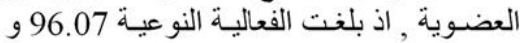

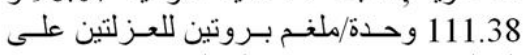
التو الي وكما موضح في الثكل (6).

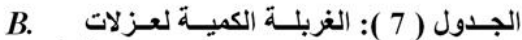
licheniformis H14

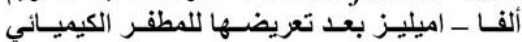

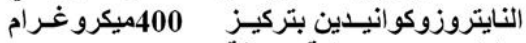
/مليليتز ويمدد زمنية مختلفة بتركية

\begin{tabular}{|c|c|}
\hline (وحدة/ملغم بروتين) & رمز العزلة \\
\hline 39.16 & HMl \\
\hline 46.64 & HM2 \\
\hline 80.06 & HM3 \\
\hline 100.94 & HM4 \\
\hline 45.47 & HM5 \\
\hline 21.46 & HM6 \\
\hline 88.41 & HM7 \\
\hline 71.01 & HM8 \\
\hline 73.09 & HM9 \\
\hline 43.85 & HM10 \\
\hline
\end{tabular}

تعيين الظروف البيئية المثلى لانتاج الانزيح: تحديد المصدر الكربوني الامثل لانتاج الانزيم: لانئين

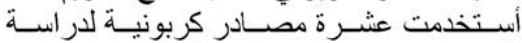

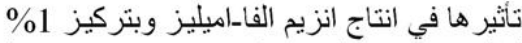

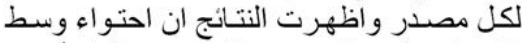

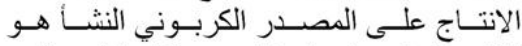

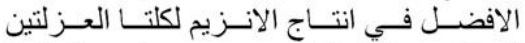
B.licheniformis المحليتـين الطـافرتين الفين HM4 B.licheniformis وHM14 الفعالية النو عية لهما 100.94و 99.5 وحدة/ملغم بروتين بوجـود النشـأ مصـدر أ وحيدأ للكربـون و على التو اللي وكما موضح في الثكل (4).

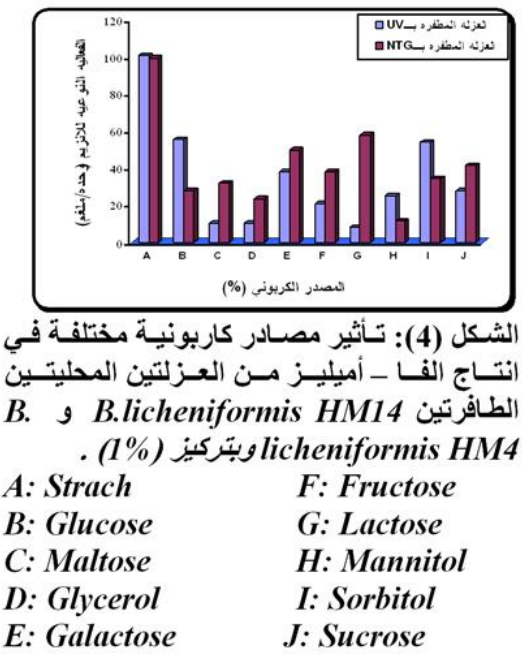




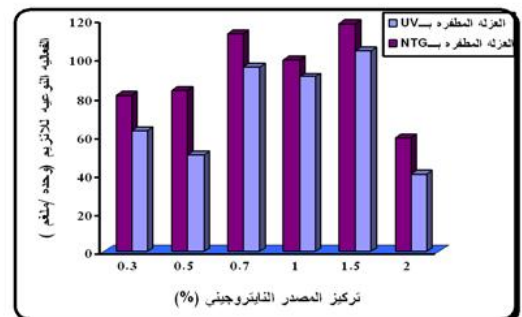

الشكل (7): تأثير تر اكيز مختلفة للببتون (0.3 -

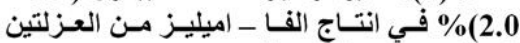

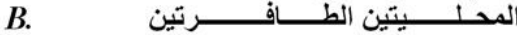

B. و licheniformis HM14 licheniformis HM4

تعيـين درجـة الحــرارة المثلــى فـي إنتاجيـة الأنزيم: - لوين

درس تأثبرمدى من درجـات الحرارة في انتاج

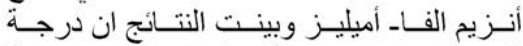

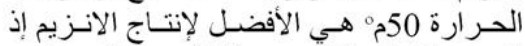

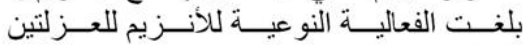
B.licheniformis المحليت لبنين الطـافرتين HM4, B.licheniformis HM14 112.08 121.83 وحدة/ ملغم بروتين و على ولى

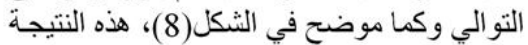
جاءت مطابقة لما ذكره [17,15] حيث لاحظوا

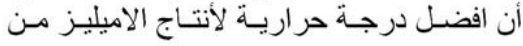
بكتريا Bacillus sp. هو ان

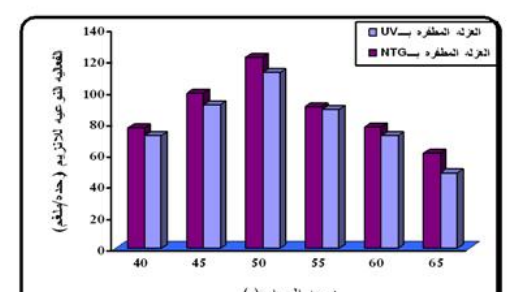

الشكل (8): تـأثير درجات حراريـة مختلفة (40 -

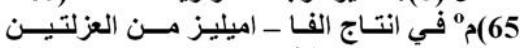

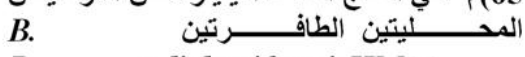
B. I licheniformis HM14 .licheniformisHM4

تحديــد الــرقم الـهيــروجينـي الأمثـل لإنتـــاج الانزيم: - احدئ

أختبـرت قابليـة العـزلتين المحليتـين الطـافرتين B.licheniformis HM4 B.licheniformisHM14 على انتاج الفاـ أميليز

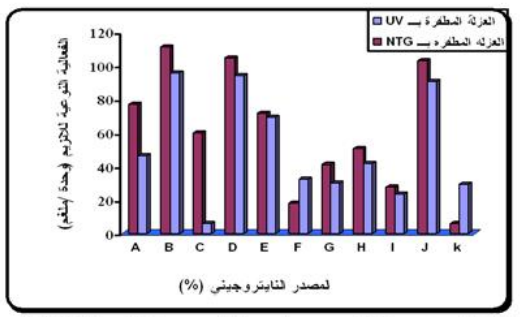

الشكل (6): تأثير مصادر نايتروجينية مختلفة في أنيا

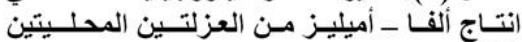
B. B.licheniformisHM14 الطـرتين الفزين اوبتركيز (0. 7icheniformisHM4
A: مستخلص اللحم
G: كبريتات الأمونبيوم
B: الببتهون اللتحن

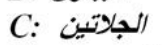
H: خلاصة الخمبيزة الأبرم
D: ترات الصودييوم: البونين
I: الكاز التبين
تلترات البوتاسيوم :
E: Kلاصة الخمبيرة + الببتهون :
F: التريتون اليفريا

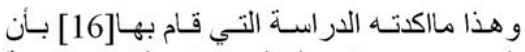

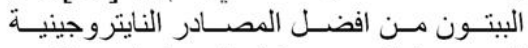

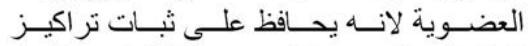

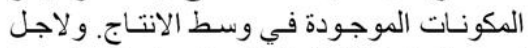

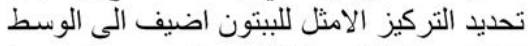
الانتاجي بتر اكيز مختلفة بوصنه مصدر أ وحيدا

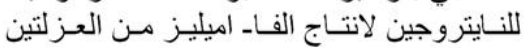

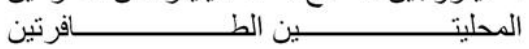
و $\quad$ B.licheniformisHM14 B.licheniformis HM4

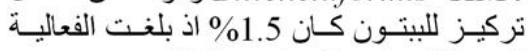
النو عية للعزلتين المحليتين الطـافرتين 104.42

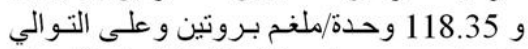

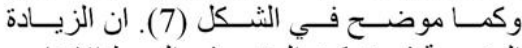
المتدرجة في تركيز البيتون في الوسط الانتاجي البي الزي

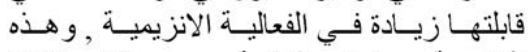

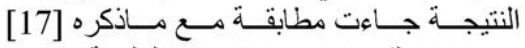

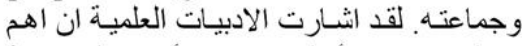

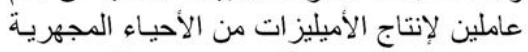

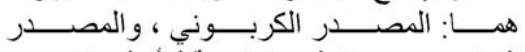

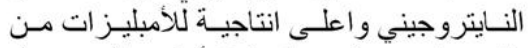

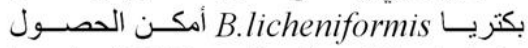
عليها عندما تكون النسبة بين C/N في الوسط الانتاجي هي (1.0)[16] 


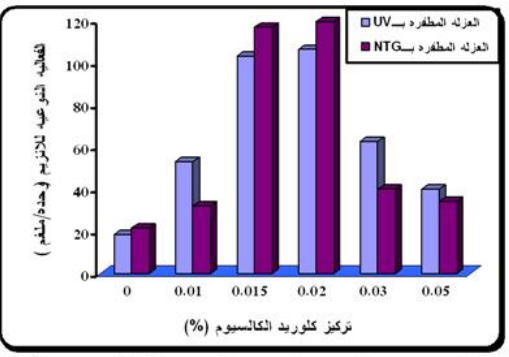

الثكل (10): تحديد تركيز كلوريد الكالسيوم الأمثل

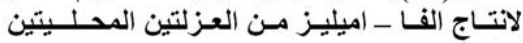

B. و B. licheniformisHM14

$$
\text { الطـافـرتين }
$$

\section{.licheniformisHM4}

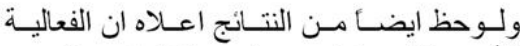

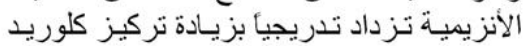

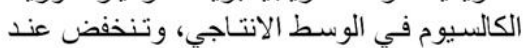

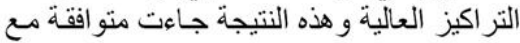

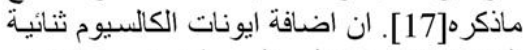

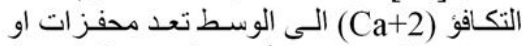

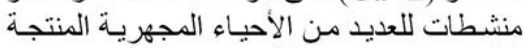

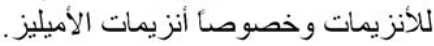

تحديد مدة الحضانة المثلى لإنتاج الأنزيم:

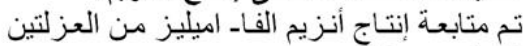

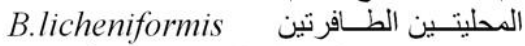
زي مدد زمنية مختلفة ـ واظهرت النتائج ان افضل إنتاج

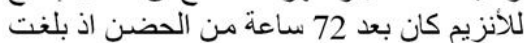

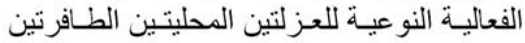

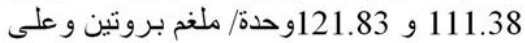

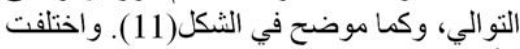
الأدبيات العلميـة في تحديد المدة المثلى الميل لإنتـاج

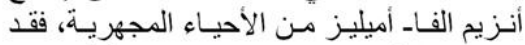

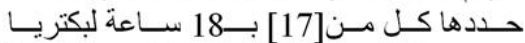
لإق Bacillus sp.

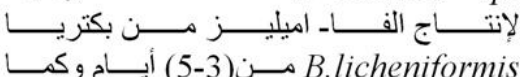

ذكره]19]
باسـتخدام الوسـط الإنتـاجي بأرقـام هيدروجينيـة

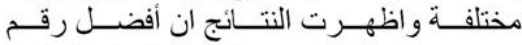

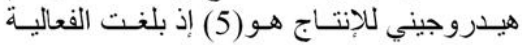
التو عية للعزلتين المحليتين الطافرتين بلنين 111.38 و 122.52 وحدة/ ملغم بروتين التين، و وعلى التين التو اللي

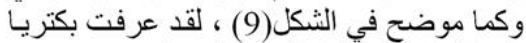

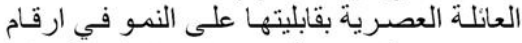

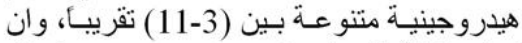

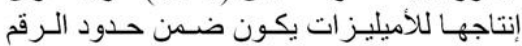
الهيدروجيني الأمثل لنمو ها.

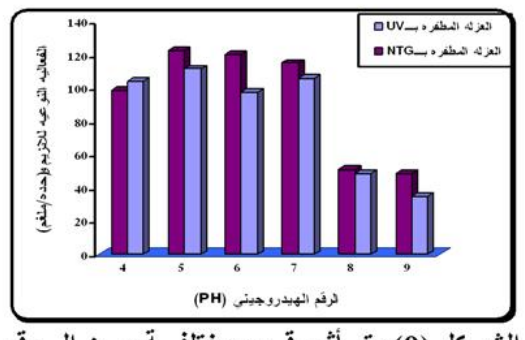

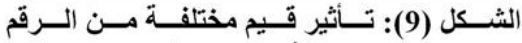

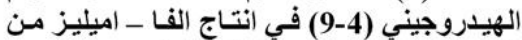

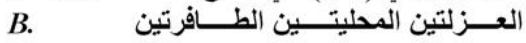

B. و licheniformisHM14 .licheniformisHM4

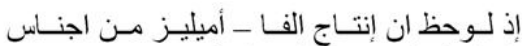

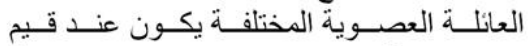

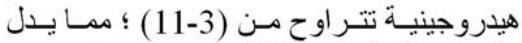

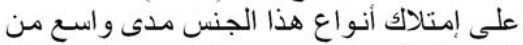

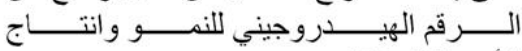
الأنزيم[18,15]

تحديـ التركيز الأمثل لكلوريــ الكالسيـيوم لإنتـاج الأنزيح: أستعملت تر اكيز مختلفة من كلوريد الكالسيوم الأليو

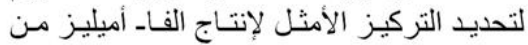

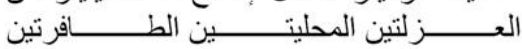
B.licheniformis HM4, B.licheniformis

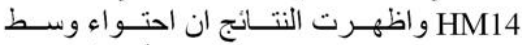
الإنتاج على تركيز 0.02\% هو الأفضل لإنتاج

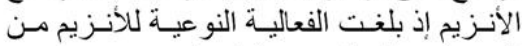

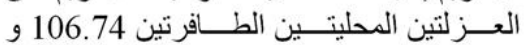

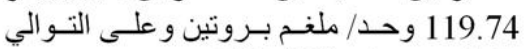
وكما موضح في الثكل(10) 
Bacillus sp. Strain Ts- 23 and it's Expression in Escherichia coli. J. Appl. Microbiol. 82: 325- 334.

9. Bradford, M.1976. A rapid and sensitive method for the quantitation of micro organism quantities of protein using the principles of protein - dye binding. Anal. Biochem. 72: $248-254$.

10. Gerhardt, P.; Murray, R.G.E.; Costilow, R.N.,; Nester, E.W.; Wood, W.A.; Krieg, N.R. and Phillips, G.b. 1981. Manual of Methods for general Bacteriology. Section II, p.p. $221-242$.

11. Carrasco, A and Soro, C.1987. Mutagenesis of Clostridium butyricum. J. Appl. Bacteriol. 63: $539-543$.

12. Mitra, S. 1996.Genetic Egineering. Principles and practice. p.p: $437-$ 453.

13. Parry, J.M.; Turnbull, P.C. and Gibson, J. R. 1983. Methods and characterization tests. In: Acolour Atlas of Bacillus sp. Wolf medical publication Ltd.

14. Slavnova, V.S.; ChigaLeichik, A.D.; Mazanov, A.L.; Shevtsov, V.V. 1986. Chemical Mutagenesis and use of indirect enzymatic criteria for selecting virulent clones of Bacillus thuringiensis. Prik. Biokhim. Micrbiol. 22(4): $543-547$.

15. UI - Haq, I.; Rani, S.; Ashraf, H. and Qadeer, M.A. 2002. Biosynthesis of Alpha-amylase by chemically treated Mutant of Bacillus subtitis. J. Biolo. Sci. 2(2): $73-75$.

16. Aiyer, P.V.D. 2004. Effect of $\mathrm{C}: \mathrm{N}$ ratio on alpha - amylase production by Bacillus licheniforms sp.T 27. African. J. Biotechnol. 3(10): 519 - 522 .

17. Lin, L.L.; Hsu, WH and Chu, WS. 1998. Production and properties of a raw starch- degrading amylase from the thermophilic and al

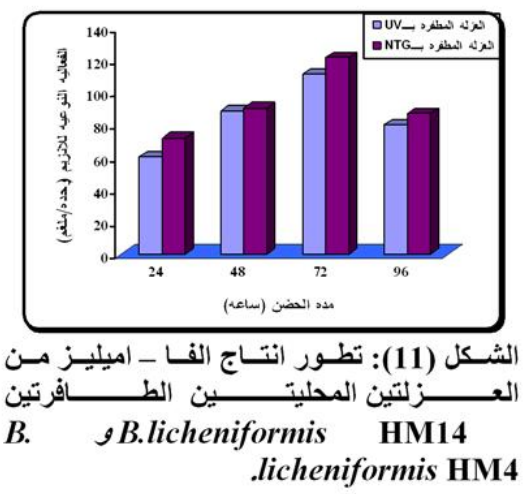

المصادر:

1. Reddy, N.S.; Nimmagadda, A. and Rao, K. R. S. S. 2003. An overview of the microbial $\alpha_{\text {- }}$ amylase family. Afri. J. Biotechnol. 2(12): 645-648.

2. Cornelis, P. 1987.Microbial amylase . Microbiol. sci. 4(11): $342-343$.

3. Pandey, A.; Nigma, P.; Soccal, C.R.; Soccal, V.T.; Singh, D. and Mohan, R. 2000. Advances in Microbial amylase. Biotechnol. Appl. Biochem. 31: 135- 152.

4. Perry, J.J. and Staley, J.J. 1997. Microbiology: Dynamics and Diversity, P.P. 304- 312. Saunders college publishing.

5. Duguid, J.P. 1996. Genus Bacillus. In: "Collee, J.G.; Fraser, A.G.; Marmion, B.P. and Simmons, A. (14th ed.)". Practical Medical Microbiology. Vol. 1. Mackie and McCartney. p.p. $131-149$.

6. Teodoro, C.E. and Martins, M.L.L. 2000. Culture conditions for the production of thermostable amylase by Bacillus sp. Brazil. J. Microbiol. 31: 1-9.

7. Toye Ekunsaumi, 2001. uw Washington country. Laboratory production and assay of amylase by Fungi and Bacteria

8. Lin, L.L.; Hsu, WH and Chu, WS. 1997. A gene encoding for $\alpha_{\text {- }}$ Amylase from thermophilhc 
licheniformis. J.Bacteriol. 121:848856.

19. Saito, N. 1973. A thermophilic Exracellular $\alpha$-amylase from Bacillus licheniformis. Arch. Biochem. Biophys. 155: 290 - 298. kaliphilic Bacillus sp. Ts- 23. Biotechnol. Appl.Biochem. 28: 6168.

18. Satio, N. and Yamamoto, K. 1975. Regulatory Factors affecting $\alpha$ amylase Production in Bacillus

\title{
Improvement of thermostable productivity $\alpha$-amylase from local isolate Bacillus licheniformis H14.
}

\author{
Hala M. Ali *
}

Ghazi M. Aziz *

Subhi J. Hamza*

*University of Baghdad /College of Science / Department of Biotechnology

\begin{abstract}
:
(28)Bacterial local isolates of Bacillus $s p$. were obtained from soil samples. Isolates were tested for thermostable alpha- amylase production on solid media; fifteen isolates were able to develop clear zone around the bacterial growth after floating the plates with iodine reagent (Lugol's solution). There were further tested in submerged culture which led to selection of Bacillus sp. H14since it was the most efficient .Microbial and biochemical tests showed that the local isolate Bacillus $s p . \mathrm{H} 14$ was refered to the species B.licheniformis that signed as $\mathrm{H} 14$ was refered to the species B.licheniformis H14 .,To get ahigher yield of alpha - amylase(48.70unit/mg protein) production from the local isolate B.licheniformis $\mathrm{H} 14$. This study used different mutation ways such as physical way by using the physical mutagen (ultraviolet light) and chemical way by using the chemical mutagen (nitrosoguanidine). Physical mutation results showed that the local isolate B.licheniformis HM14 get higher yield of alpha - amylase production(102.10 unit/mg protein) according to killing percentage $(90 \%)$ while the chemical mutation results showed that the local isolate B.licheniformis HM4 get higher yield of alpha -amylase production(100.94 unit/mg protein) from the two mutant local isolates (HM14 and HM4)were the best carbon source starch $(1.5 \%)$, peptone $(1.5 \%)$ as nitrogen source, calcium chloride $(0.02 \%)$, sodium chloride $(0.05 \%)$, magnicium phosphate $(0.05 \%)$, sodium di -hydrogen phosphate $(0.16 \%)$, at initial $\mathrm{pH}(5)$ and inoculum size $1 * 10^{8}$ $\mathrm{cfu} / \mathrm{ml}$ at $\left(50^{\circ} \mathrm{C}\right)$ For $(72)$ hours, using shaking incubator at $(150) \mathrm{rpm}$.
\end{abstract}

